\section{SONIC TOOTHBRUSH ACCREDITED BY BDHF}

Sonicare for Kids has recently been accredited by the British Dental Health Foundation following assessment by a panel of dental experts who verified a series of clinical claims for the brush. The newly accredited brush will form one of the centrepieces of the Philips stand at BDTA Dental Showcase.

Delegates will be able to learn about the benefits of using the sonic children's toothbrush with their younger patients: it has been proven to remove significantly more plaque than a manual toothbrush; encourages children to brush for longer; and helps establish healthy brushing habits early on.

Also on show will be the FlexCare+, Philips' latest innovation, designed for patients with periodontal conditions and shown to significantly improve gum health in two weeks.

Among other products in the portfolio is the HealthyWhite brush, designed for patients with a particular interest in aesthetic outcomes.

REVOLUTIONARY NEW MATERIAL

Septodont has recently launched their breakthrough new product, Biodentine, and will be in attendance at BDTA Dental Showcase on stand Q09.

This cutting edge technology which, for the first time, offers a bioactive substitute to dentine, could revolutionise dental practice. Biodentine is the first all-in-one, biocompatible and bioactive material that can be used wherever dentine is damaged, both in the

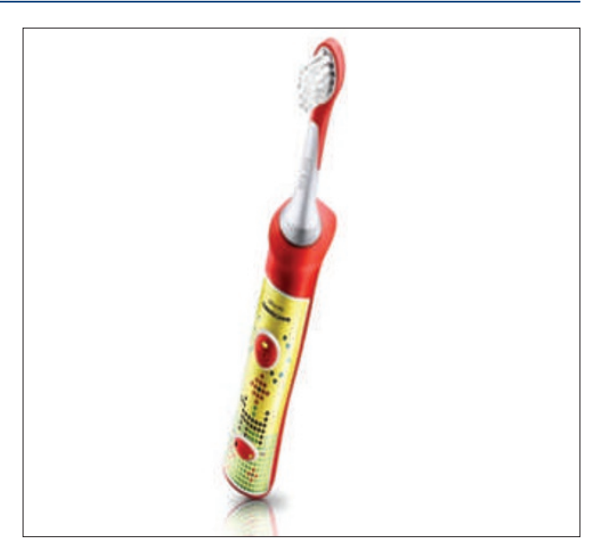

Philips will be unveiling a new brand direction for their Sonicare range at Dental Showcase and will be demonstrating how its business teams will be working more closely to help professionals achieve even more impressive clinical and business results. A range of support materials for dental professionals will also be on display.

To learn more and for a number of special offers, visit stand P09.

Reader response number 65

crown and the root.

The product preserves pulp vitality, promotes pulp healing and is able to replace the natural dentine with the same mechanical properties. Biodentine allows dentists to achieve biomimetic mineralisation within the depths of a carious cavity. It also has the potential to revolutionise the management of the deep carious cavity in operative dentistry, whether or not the pulp is exposed.

Reader response number 66

\section{COSMETICALLY ENHANCED DENTAL CHAIR}

At BDTA Dental Showcase Takara Belmont will be displaying the recently launched treatment centre Cleo II and the new Clair Chair, a stand alone chair that can now be purchased individually.

The Cleo II treatment centre is cosmetically enhanced with luxurious upholstery for comfort and a seamless one piece seat and leg rest that makes it easy to clean. The Cleo II also has the functional benefits of a folding leg rest, an armrest that rotates $180^{\circ}$ to facilitate patient access, and a $90^{\circ}$ cuspidor swivel action.

The Clair Chair, part of the Cleo II treatment centre, is available in two models, the 050 and the 055 . The 055 offers a power headrest, two preset positions, last position memory and auto-return, foldaway detachable armrests and is suitable for right and left handed installation. The 050 boasts the same features but with a twin articulating headrest.

Visit Takara Belmont on stand H12.

Reader response number 67

\section{THE LATEST ADVANCES} IN SOFTWARE

Carestream Dental (formerly PracticeWorks) is confident that their products, featuring the latest advances in dental software and technology, will fit right into the BDTA Dental Showcase's theme of 'innovation, integration and education'.

Carestream Dental will demonstrate to delegates what can be achieved using their interactive 3D Oralinsights system, which is currently revolutionising child oral hygiene education. Carestream Dental will also unveil several new and exciting products over the course of three-day event.

Carestream's other solutions include the Kodak 1500 intraoral camera and the newly updated R4 Clinical+ practice management software.

Head to stand Q07.

Reader response number 68

\section{THE RIGHT BRUSH THE RIGHT WAY}

Among the products Oral-B will be presenting at this year's Dental Showcase on stand will be their Professional Only Packs. These include an educational DVD and a whole range of replacement heads free of charge with every Professional Care and Triumph product sold through dental practices.

The Professional Only Packs will help ensure patients use the right type of brush the right way. They will also include the improved Precision Clean brush head which now has 29\% more bristles.

On stand N02 Oral-B representatives will be available to advise visitors on the various means by which practices can gain complimentary CPD hours. These include through Dental Summary Review, Lunch and Learn demonstrations and Up To Date evening seminars. Oral-B funds a variety of ways dental professionals can meet their educational requirements, recognising that different individuals have different needs and preferences.

Reader response number 69 